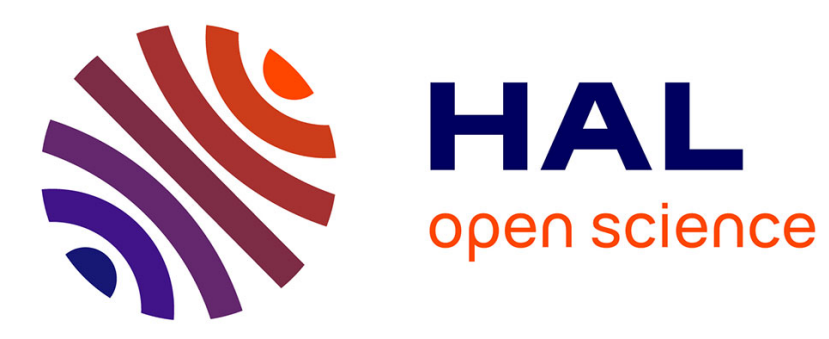

\title{
Power Maximization of a Closed-orbit Kite Generator System
}

\author{
Mariam Ahmed, Ahmad Hably, Seddik Bacha
}

\section{To cite this version:}

Mariam Ahmed, Ahmad Hably, Seddik Bacha. Power Maximization of a Closed-orbit Kite Generator System. CDC 2011 - ECC 2011 - 50th IEEE Conference on Decision and Control and European Control Conference, Dec 2011, Orlando, Floride, United States. hal-00619320

\section{HAL Id: hal-00619320 https://hal.science/hal-00619320}

Submitted on 6 Sep 2011

HAL is a multi-disciplinary open access archive for the deposit and dissemination of scientific research documents, whether they are published or not. The documents may come from teaching and research institutions in France or abroad, or from public or private research centers.
L'archive ouverte pluridisciplinaire HAL, est destinée au dépôt et à la diffusion de documents scientifiques de niveau recherche, publiés ou non, émanant des établissements d'enseignement et de recherche français ou étrangers, des laboratoires publics ou privés. 


\section{Power Maximization of a Closed-orbit Kite Generator System}

\author{
Mariam Ahmed* \\ Grenoble Electrical Engineering \\ Laboratory (G2ELab) \\ 38402 Saint-Martin d'Heres, \\ France
}

\author{
Ahmad Hably** \\ GIPSA-lab -ENSE3 BP 46 \\ 38402 Saint-Martin d'Heres, \\ France
}

\author{
Seddik Bacha*** \\ Grenoble Electrical Engineering \\ Laboratory (G2ELab) \\ 38402 Saint-Martin d'Heres, \\ France
}

\begin{abstract}
This paper presents a control scheme of a closedorbit kite generator system (KGS). Such a system is divided into two main parts: A kite with its orientation mechanism and a power transformation system. Starting from a given closed orbit, the optimal tether's length rate variation (tether radial velocity) and the optimal orbit's period are found. For the kite's orientation, a kite model is chosen and a trajectory-tracking control is developed. The power transformation system controls the tether radial velocity and transforms the mechanical energy generated by the kite into electrical energy that can be added to the grid. The proposed control strategy is tested on a Matlab/Simulink model of the KGS.
\end{abstract}

\section{NOMENCLATURE}

$\begin{array}{ll}\text { KGS } & \text { Kite generator system } \\ \text { SM-PM } & \text { Synchronous Machine with Permanent Magnets } \\ \rho_{a} & \text { Air density } \\ C_{L} & \text { Lift coefficient } \\ C_{D} & \text { Drag coefficient } \\ G_{e} & \text { Kite aerodynamic efficiency coefficient } \\ m & \text { Kite's mass } \\ A & \text { Kite's area } \\ R & \text { Rotor diameter } \\ \Omega & \text { Rotor rotational velocity } \\ r_{0} & \text { Initial tether length } \\ x & \text { Kite's state vector } \\ v & \text { Normalized tether radial velocity } \\ w_{\|} & \text {Normalized crosswind velocity } \\ J_{0} & \text { Normalized mean generated power } \\ T & \text { Orbit's period } \\ \psi & \text { Kite's roll angle } \\ F^{c, t r c} & \text { Tether's traction force } \\ P_{M} & \text { Mean generated power } \\ C_{R} & \text { Kite's resistive torque } \\ C_{G} & \text { Generator torque } \\ & \end{array}$

\section{INTRODUCTION}

Wind energy is considered as an ideal renewable energy source, since it is infinitely sustainable and clean. A conventional wind turbine is a machine that converts wind's kinetic energy into electrical energy through a rotor coupled with an alternator. This system is widely studied but still some questions regarding its wide integration to the electrical grid, ancillary services, low voltage ride, and disturbances decoupling. Wind turbines have a number of advantages. They require no fuel and they do not produce niether toxic nor radioactive wastes. However, these huge

\footnotetext{
*Corresponding author

Mariam.AHMED@g2elab.grenoble-inp.fr

**Ahmad. Hably@grenoble-inp. fr

***Seddik. Bacha@g2elab.grenoble-inp.fr
}

constructions are fixed and limited. Such a wind turbine reaches a maximum height of $200 \mathrm{~m}$ where the wind is still unstable with an acceptable speed. In fact, strong wind could be present at higher altitudes with little or no wind at low altitudes.

The research for stronger and more regular winds led to the birth of several solutions such as balloons, airborne wind turbines and tethered airfoils (kites). The principle of the balloon, developed by Magenn Power Inc, is as follows: a helium-filled balloon stationary at a height of $200 \mathrm{~m}$ to $350 \mathrm{~m}$ rotates around a horizontal axis connected to a generator. The energy produced is transmitted to the ground by a conductive tether. The second solution offered by Sky WindPower, Joby energy [7], or Makani Power (funded by Google)[8], would be to use airborne wind turbines to harness energy directly in high-altitude winds and to send it to the ground by cables. This system has some technical complexities and high cost with a significant risk related to its weight. The third option is to use power kites as renewable energy generators such as the "Kite Wind Generator" of Politecnico di Torino [5] and "Laddermill" of the Delft University of Technology [11]. All these constructions have practically the same operation principle, which is to mechanically drive a ground-based electric generator using one or several tethered kites. Energy is extracted from high altitudes by controlling the kite to fly around a lying-eight orbit with high crosswind speed. This develops a large pulling force that turns the generator, thus generating electricity. However the kite should be always redrawn to its initial position, consuming energy as doing so.

In this context, the last solution based on kites is studied. The objective is to improve the traction/recovery cycle through controlling the position and movement of the kite around a predefined optimal trajectory that depends on wind's direction and speed.

As shown in Fig.1, a kite generator system (KGS) is a kite that collects wind energy and transforms it into a torque applied on a synchronous machine with permanent magnets (SM-PM) situated on ground. This leads to production of an alternative electrical energy with variable frequency. The machine is coupled with the grid through a power electronics interface. An energy storage can be integrated in order to provide the energy needed during the system's recovery phase. The aim of this paper is to simulate the whole KGS using Matlab/Simulink software. In order to do so, a kite simplified mathematical model was chosen, as well 


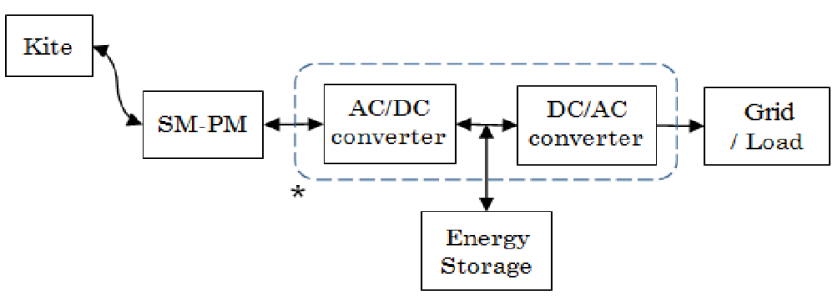

Fig. 1. Kite Generator System Block diagram, *Power electronics interface.

as, an optimal approach proposed in [3] to seek the optimal tether radial velocity and the orbit's period. These variables are implemented using a fast simple algorithm with the possibility of real-time implementation. Knowing that the KGS is a nonlinear complex system, a predictive control strategy is applied to achieve orbit and velocity tracking. The resulting traction torque and tether radial velocity are then applied to a Simulink-model of the power transformation system in order to find the produced electrical power.

The paper goes through three main sections. The first presents the studied kite simplified model, the produced mechanical power expression for the simplified mathematical model developed in [2], and an introduction of the power transformation system. The second section presents the control strategy. It includes the search of the optimal tether radial velocity and orbit's period. The optimal predictive orbit tracking problem is also presented. In section IV, simulation results of three chosen orbits with a comparative study are shown. The paper ends with conclusions and future work.

\section{THE PROBLEM DESCRIPTION}

The chosen structure, as show in the Fig.2, is a kite connected by a tether wound around a drum that is coupled with the rotor of a permanent-magnet synchronous electric machine through a gearbox. The kite should follow a lying-

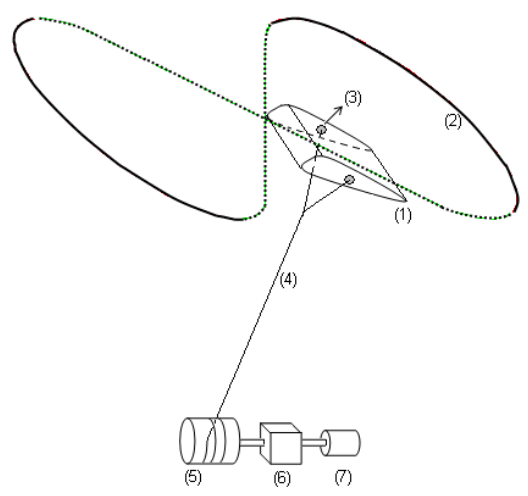

Fig. 2. Kite wind generator structure: 1) Kite; 2) Lying-eight orbit; 3) Orientation mechanism; 4) Tether; 5) Drum; 6) Gearbox; 7) Electrical generator.

eight orbit that ensures the non-tangling of the tether and the maximization of the apparent wind blowing against the kite, resulting in a high lift force. The orbit is defined by the following parametric equations:

$$
\begin{aligned}
& \theta(\tau)=\theta_{0}+\cos (R o t) \Delta \theta \sin (2 \tau)-\sin (R o t) \Delta \phi \sin (\tau) \\
& \phi(\tau)=\phi_{0}+\sin (R o t) \Delta \theta \sin (2 \tau)+\cos (\text { Rot }) \Delta \phi \sin (\tau)
\end{aligned}
$$

The signification of each symbol is shown on Fig.3.

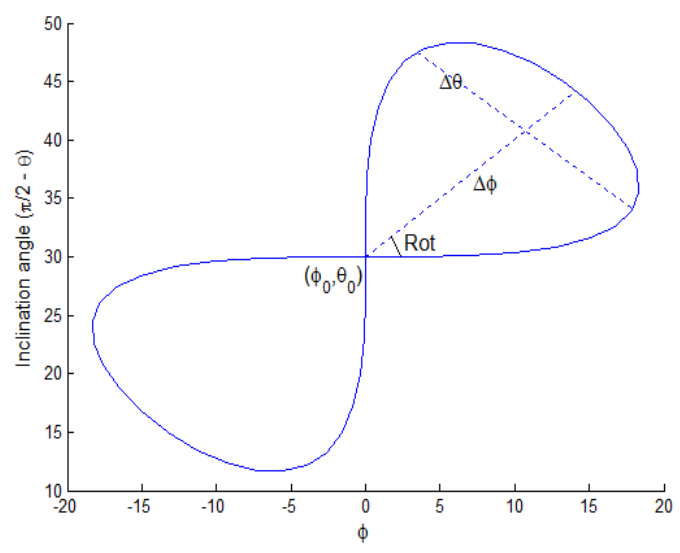

Fig. 3. Orbit parameters.

There are two types of orbits: closed and opened. In the closed orbit, both the traction and recovery phase take place in the orbit's period. In the opened orbit and during the traction phase, the kite altitude increases reaching its maximum, then during the recovery phase it is wound down. In this paper, the closed orbit is focused on. In order to maximize the power generation, a suitable orientation and velocity control should be applied on a kite's model that should be chosen. This needs wind speed measurement. However, to give up the usage of on-board wind speed sensors, two methods are proposed: wind speed estimation [9], or usage of already existing wind curves function of altitude, and then application of maximum power point tracking (MPPT) algorithm [1] to ensure maximum energy production. It is assumed that wind speed is known with an acceptable error.

\section{A. The Kite's Model}

The dynamical model originally developed in [6] and used in [4] is adopted here. Neglecting the tether's weight and its drag force, the forces acting on the kite written in the cylindric coordinates are:

$$
\begin{aligned}
& F_{\theta}=F_{\theta}^{\text {grav }}+F_{\theta}^{a p p}+F_{\theta}^{a e r} \\
& F_{\phi}=F_{\phi}^{\text {grav }}+F_{\phi}^{a p p}+F_{\phi}^{a e r} \\
& F_{r}=F_{r}^{\text {grav }}+F_{r}^{a p p}+F_{r}^{a e r}-F^{c, t r c}
\end{aligned}
$$

with $F^{g r a v}$ is the gravity force and

- $F^{a p p}$ the apparent force with $m$ the kite mass:

$$
\begin{aligned}
& F_{\theta}^{a p p}=m\left(\dot{\phi}^{2} r \sin \theta \cos \theta-2 \dot{r} \dot{\theta}\right) \\
& F_{\phi}^{a p p}=m(-2 \dot{r} \dot{\phi} \sin \theta-2 \dot{\phi} \dot{\theta} r \cos \theta) \\
& F_{r}^{a p p}=m\left(r \dot{\theta}^{2}+r \dot{\phi}^{2} \sin ^{2} \theta\right)
\end{aligned}
$$

- $F^{a e r}$ the aerodynamic force with two components, the lift force $F_{L}$ that is perpendicular to the kite's surface, 
and the drag force $F_{D}$ which has the effective wind's direction:

$$
\begin{aligned}
& F_{L}=\frac{1}{2} \rho_{a} A C_{L}\left|\vec{W}_{e}\right|^{2} \\
& F_{D}=\frac{1}{2} \rho_{a} A C_{D}\left|\vec{W}_{e}\right|^{2}
\end{aligned}
$$

where $A$ is the kite's surface, $\rho_{a}$ is the air density, $C_{L}$ is the drag coefficient and $C_{D}$ is the lift coefficient.

- $F^{c, t r c}$ the traction force of the lines.

The aerodynamic force direction is controlled by the roll angle $\psi$ which is defined by:

$$
\psi=\arcsin \left(\frac{\Delta l}{d}\right),
$$

with $d$ being the distance between the two lines fixing points at the kite and $\Delta l$ is the difference between the lines length.

\section{B. Mechanical Power Generation for the Simplified Mathe- matical Model}

As mentioned earlier, the weight of the tether and its drag force are not taken into account in the system modeling. As well as it is considered that the kite has a high lift over drag ratio $C_{L} / C_{D}$, which is equivalent to a high value of the kite aerodynamic efficiency coefficient $G_{e}$. The system average mechanical energy over one period $T$ is:

$$
\bar{P}_{M}=\frac{1}{T} \int_{0}^{T} F^{c, t r c}(t) V_{L}(t) d t
$$

where $F^{c, t r c}$ is the traction force acting on the tether, and $V_{L}$ is the tether radial velocity).

According to [3], by changing the integral time variable $t \in$ $[0, T]$ to the dimensionless parameter $\tau \in[0,2 \pi]$, and making use of the substitution $V_{L}(t)=V v(\tau)$, equation (6) can be expressed as follows:

$$
\bar{P}_{M}(v)=\frac{1}{2} \rho_{a} A C_{L} G_{e}^{2} V^{3} J_{0}(v)
$$

where $V$ is the wind speed amplitude and

$$
J_{0}(v)=\frac{\int_{0}^{2 \pi}\left(w_{\|}-v\right) v h(\tau) d \tau}{\int_{0}^{2 \pi} \frac{h(\tau)}{w_{||}-v} d \tau}
$$

with $h(\tau)=\sqrt{d \theta^{2}+d \phi^{2} \sin ^{2}(\theta)}$ and $w_{\|}=\sin (\theta) \cos (\phi)$. As noticed, $J_{0}$ represents the normalized ${ }^{1}$ average power $\bar{P}_{M}$.

\section{Power Transformation System}

In order to integrate the kite's generated mechanical power into the electrical grid, a power transformation system is needed to transform this energy into electrical power with a fixed voltage and frequency. Such a system consists of:

1) A synchronous machine with permanent magnets (SMPM): It can act as a generator which transforms the kite's mechanical energy to electrical energy with a variable frequency, and as a motor to provide the needed power in the kite recovery phase.

\footnotetext{
${ }^{1}$ Normalizing coefficient is : $\rho_{a} A C_{L} G_{e}^{2} V^{3}$
}

2) A power electronics interface that ensures isolation between the SM-PM and the electrical grid or the connected loads, and at the same time offers the possibility of power flow from/to the SM-PM.

Each part of the power transformation system is modeled. The resulting models are implemented in Matlab/simulink environment, in addition to PI velocity and currents loops. The Simulink model (Fig.4) is useful to perform a preapplication test of the ability to use a certain SM machine, to ensure the operation of the correctors, as well as giving an idea about the extracted power.

The SM-PM's rotational velocity control as well as the generator torque control are guaranteed by the (SM-PM) side converter. It should be kept in mind that the velocity control is equivalent to controlling the tether radial velocity, $V_{L}=\Omega / R$. Fig.5 presents the (SM-PM)-side converter's control diagram: The kite applies a resistive torque $C_{R}$ that gives, when inserted in the mechanical equation, the rotation velocity $\Omega$. This velocity is corrected using a PI controller that yields a reference generator torque $C_{G r e f}$. When adapting Park representation of the synchronous machine and the converter, controlling the generator torque $C_{G}$ is equivalent to control the current $i_{s q}$ when asserting $i_{s d}=0$.

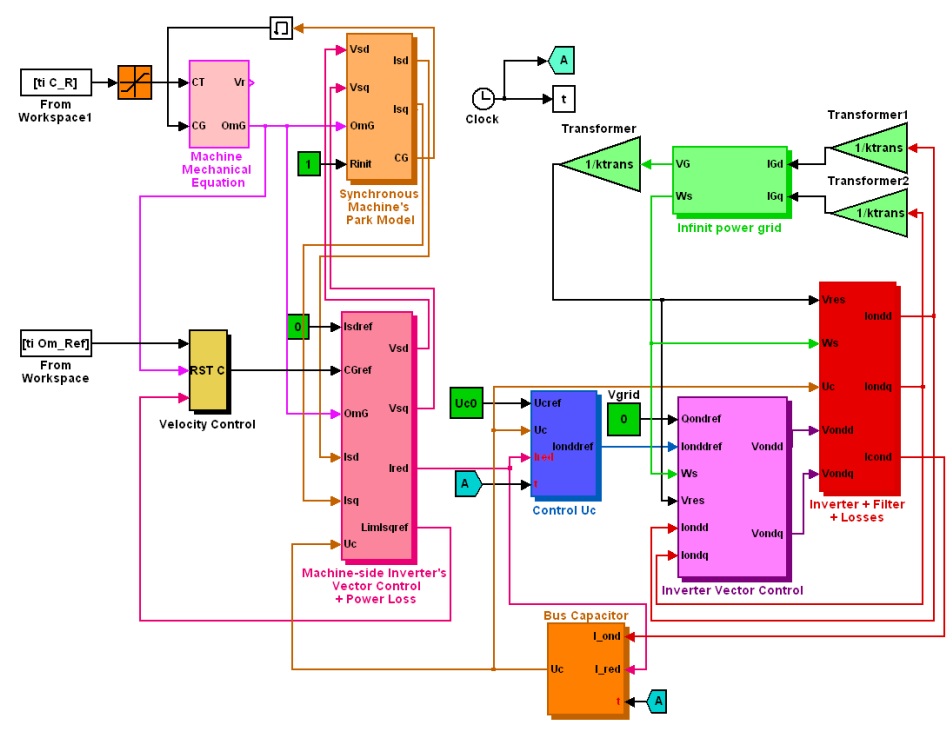

Fig. 4. Power transformation system Simulink model.

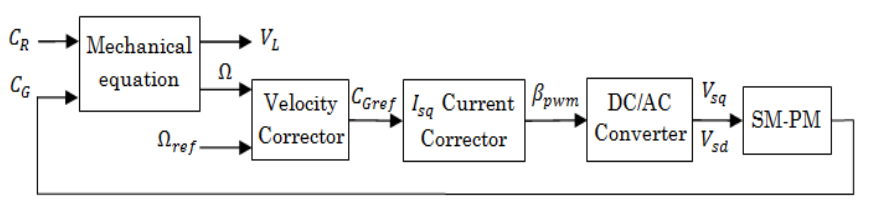

Fig. 5. Converter control Diagram.

\section{CONTROL STRATEGY}

The control strategy proposed in this paper is divided into two parts. The first aims at generating an optimal reference orbit with an optimal tether radial velocity. In the second 
part, a Model Predictive Control (MPC) strategy that allows an optimal tracking under constraints of the generated orbit is implemented.

\section{A. Reference Orbit Generation}

In this section, the optimal reference orbit based on the work of [2] was found. Orbit optimization aims at having a high crosswind speed, which develops high traction force and thus higher power production. The crosswind speed is expressed in [3] by: $\left|W_{e}^{p}\right|=G_{e} V\left(w_{\|}-v\right)$. This means the optimal tether radial velocity $v(\tau)$ should be found. This velocity maximizes the power produced presented earlier by the equation (8), and satisfies the closed loop orbit condition $\int_{0}^{T} V_{L}(t) d t=0$, which, for the simplified mathematical model, is expressed by:

$$
\int_{0}^{2 \pi} \frac{v h(\tau)}{w_{\|}-v} d \tau=0
$$

1) Optimal Tether Length Rate Variation (tether radial velocity): As explained in [3], the optimization problem can be found by seeking the solution of the cubic equation:

$$
v^{3}-\frac{5 w_{\|}}{2} v^{2}+2 w_{\|}^{2} v+\frac{J_{0}}{2}-\frac{w_{\|}^{3}}{2}-\frac{\lambda w_{\|}}{2}=0,
$$

where, as mentioned earlier, $J_{0}$ is a function of $v(\tau)$ and is given by the equality (8), and $\lambda$ is the Lagrangian that ensures the condition (9). In order to find the optimal velocity $\hat{v}$, that satisfies the equations $(8,9,10)$, the fixed-point algorithm is used $^{2}$. It can be resumed through the following steps:

- Find an initial guess for $J_{0}$

- Find the solution $\hat{v}$ of equation (10) as a function of $\lambda$.

- Replace the found solution in equation (9) and look for $\lambda$ that minimizes it

- Recalculate $J_{0}$ using equation (8)

- Repeat the procedure until $\left|J_{0(i)}-J_{0(i-1)}\right|<\epsilon$ with $\epsilon$ is sufficiently small.

Once found, $\hat{v}$ is used to derive the normalized ${ }^{3}$ traction force via the equation $f_{\text {trac }}=\left(w_{\|}-v\right)^{2}$ (see [3]).

2) Orbit's Period T: All done calculations and variables are functions of the dimensionless parameter $\tau$ and have a period of $2 \pi$. The orbit's time period $T$ and the relation between the time variable $t \in[0, T]$ and $\tau$ need to be defined. They are expressed by

$$
T=\int_{0}^{2 \pi} \frac{r(\tau) h(\tau)}{G_{e}\left(w_{\|}(\tau)-v(\tau)\right)} d \tau
$$

and

$$
t=\int_{0}^{\tau} \frac{r(\sigma) h(\sigma)}{G_{e}\left(w_{\|}(\sigma)-v(\sigma)\right)} d \sigma
$$

${ }^{2} \mathrm{C}$ programming language will be used to optimize time calculation ${ }^{3}$ Normalizing coefficient is : $\rho_{a} A C_{L} G_{e}^{2} V^{2}$

\section{B. Optimal Predictive Orbit Tracking}

A nonlinear Model Predictive Control (MPC) strategy was employed in order to follow the desired orbit. The control takes into account states and control constraints. The state vector of the kite generator system is $x=[\theta, \phi, r, \dot{\theta}, \dot{\phi}, \dot{r}]$. The control variables are: 1 ) the roll angle $\psi$ which controls the orientation of the kite, thus the angles $\theta$ and $\phi .2$ ) the traction force $F^{c, t r c}$ which controls the tether velocity. The cost function used expresses the distance between the current position of the kite and the referential one. Its minimization aims to converge the state to the reference orbit slowly or quickly depending on $\lambda_{1}, \lambda_{2}$ chosen values:

$$
\min _{\psi, F^{c, t r c}}\left\|\left(\ddot{x}_{r e f}-\ddot{x}\right)+\lambda_{1}\left(x_{r e f}-x\right)+\lambda_{2}\left(\dot{x}_{r e f}-\dot{x}\right)\right\|^{2}
$$

The MPC reference is generated by the optimization algorithm mentioned in section III-A. The resulting control $\psi$ is achieved through an orientation mechanism, while the control of the traction force is accomplished by applying a rotation velocity control of the synchronous machine. The employed control strategy applied for the Kite Generator System is clearly presented in Fig.6.

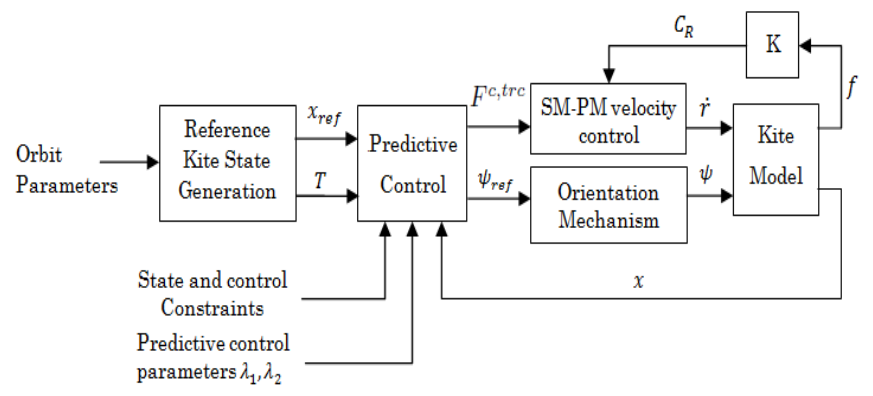

Fig. 6. Kite Generator control diagram.

\section{SIMULATION AND RESULTS}

A simplified closed-orbit KGS is taken into consideration. It supposes the possibility to know the wind speed with an accepted error. In the following tests the KGS parameters are those of Table I. The state and control constraints are the following:

$$
\begin{aligned}
\theta_{\min }=30^{\circ} & <\theta \quad<\theta_{\max }=90^{\circ} \\
\phi_{\min }=-90^{\circ} & <\phi \quad<\phi_{\max }=90^{\circ} \\
r_{\min }=90 \mathrm{~m} & <r \quad<r_{\max }=110 \mathrm{~m} \\
\dot{\psi}_{\min }=-4^{\circ} / \mathrm{sec} & <\dot{\psi} \quad<\dot{\psi}_{\max }=4^{\circ} / \mathrm{sec}
\end{aligned}
$$

with $\dot{r}_{\max }=83.3 \mathrm{~m} / \mathrm{sec}$ and $\psi_{\max }=20^{\circ}$. In order to test the control scheme proposed throughout the paper, three orbits, shown in Fig.7 with the characteristics in Table II, are applied to find their corresponding generated electrical power.

After applying the optimal predictive control for orbit tracking, the resultant tether radial velocity as well as the traction force obtained from the kite model are transformed to rotation velocity $\Omega$ and a resistive torque $C_{R}$ of the rotor. The 
transformation is done through multiplication by a constant, as in the equations:

$$
\begin{aligned}
\Omega & =\frac{V}{r_{0}} \frac{v}{K} \\
C_{R} & =\frac{1}{2} \rho_{a} A C_{L} G_{e}^{2} V^{2} r_{0} F^{c, t r c} K
\end{aligned}
$$

where $K$ is the gear box ratio. They are then applied on the power transformation system Simulink model (Fig.4).

TABLE I

Kite Generator System Parameters

\begin{tabular}{|c||c||c|}
\hline$R$ & 0.3 & Rotor Diameter $(\mathrm{m})$ \\
\hline$\Omega_{\max }$ & 25 & Maximum rotor rotation velocity $(\mathrm{rd} / \mathrm{sec})$ \\
\hline$\Gamma_{\max }$ & 22 & Motor maximum torque $(\mathrm{N} . \mathrm{m})$ \\
\hline$m$ & 2.5 & Kite mass $(\mathrm{kg})$ \\
\hline$A$ & 5 & Kite area $\left(\mathrm{m}^{2}\right)$ \\
\hline$\rho_{a}$ & 1.2 & Air density $\left(\mathrm{kg} / \mathrm{m}^{3}\right)$ \\
\hline$C_{L}$ & 1.5 & Lift coefficient \\
\hline$C_{D}$ & 0.15 & Drag coefficient \\
\hline$T_{s}$ & 0.1 & Sampling time $(\mathrm{sec})$ \\
\hline
\end{tabular}

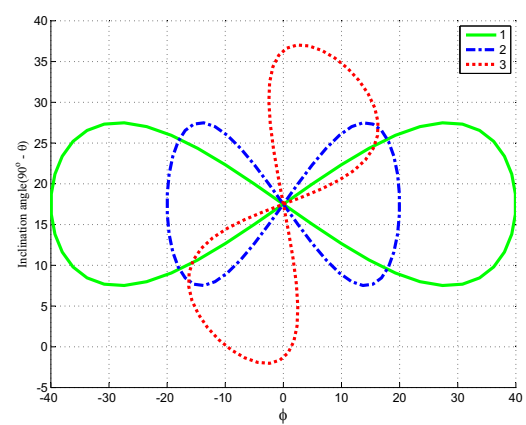

Fig. 7. Test orbits.

Fig. 8 shows the orbit tracking by applying the already explained optimal predictive control in the case of the first orbit. The period and mechanical power generated for each orbit are listed in Table III.

TABLE II

TESTING ORBITS PARAMETERS

\begin{tabular}{|c||c||c||c|}
\hline Orbit & 1 & 2 & 3 \\
\hline$\theta_{0}$ & $72.5^{\circ}$ & $72.5^{\circ}$ & $72.5^{\circ}$ \\
\hline$\Delta \theta$ & $10^{\circ}$ & $10^{\circ}$ & $10^{\circ}$ \\
\hline$\Delta \phi$ & $40^{\circ}$ & $20^{\circ}$ & $20^{\circ}$ \\
\hline Rot & $0^{\circ}$ & $0^{\circ}$ & $30^{\circ}$ \\
\hline
\end{tabular}

Sizing operation should be applied on the kite's torque and the radial velocity in order to satisfy the energy transformation system characteristics. As shown in Fig. $(9,11,13)$ energy generation is guaranteed in the three cases, with maximum electrical power generation in the case of the first orbit. An increase of orbit's rotation angle leads also an increase of generated power. Surly the electrical generated power will be larger and closer to the results found in Table III when a more

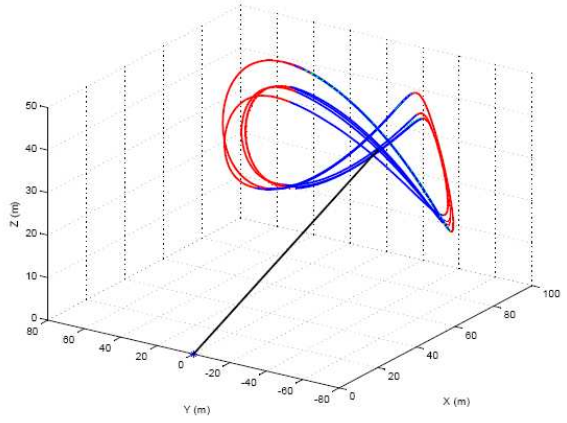

Fig. 8. Tracking orbit 1 using optimal predictive control

adapted machine is used. When applying the resulting torque and velocity on the Simulink model, after modifying the parameters of the rotation velocity PI corrector, the velocity was tracked correctly which is shown in Fig. $(10,12,14)$.

TABLE III

ORBITS' PERIOD AND MEAN MECHANICAL POWER

\begin{tabular}{|c||c|c||c|}
\hline Orbit & 1 & 2 & 3 \\
\hline Period $(\mathrm{sec})$ & 4.11 & 2.48 & 2.47 \\
\hline Mean power $(\mathrm{kW})$ & 3.818 & 1.608 & 1.801 \\
\hline
\end{tabular}
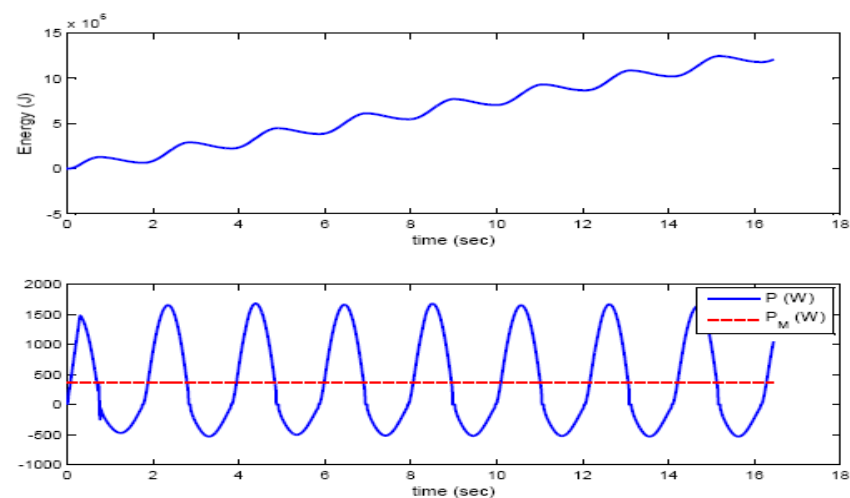

Fig. 9. Orbit 1's Power Generation, $P_{M}$ mean power.
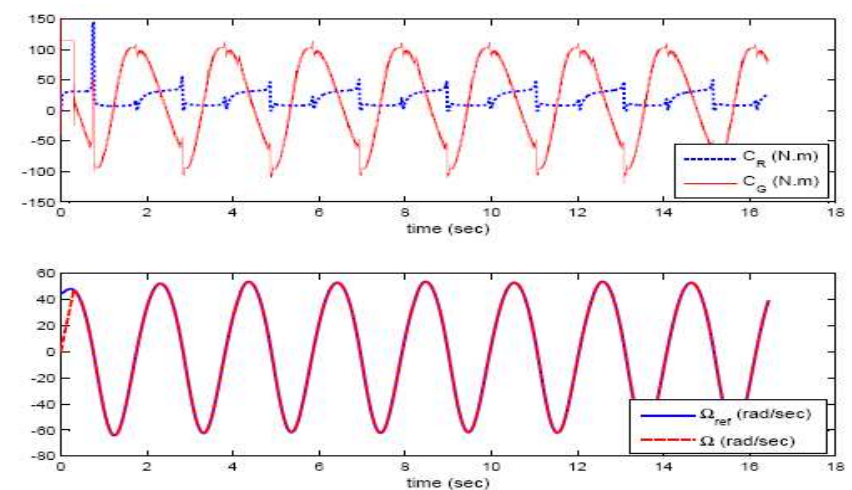

Fig. 10. Kite applied torque $\left(C_{R}\right)$, Generator Torque $\left(C_{G}\right)$ and Rotation velocity tracking for orbit 1 . 


\section{CONCLUSIONS AND FURTHER WORKS}

\section{A. Conclusions}

A closed-orbit Kite Generator System was considered in this paper. It was illustrated that for a specific eightform trajectory, the optimal tether radial velocity can be calculated, through application of a fixed-point algorithm on the simplified mathematical model.

By the application of this algorithm and using the kite's model, the generated traction force was found. This force translated to a resistive torque has been applied on a Simulink model of a synchronous machine. The machine rotational velocity was controlled to follow the optimal velocity profile (corresponding to the optimal tether radial velocity ) while transforming the kite's mechanical energy into electrical. By means of the power transformation system built in Simulink, the produced electrical energy was calculated for three different closed orbits. It was found that produced electrical power was proportional to the orbit's period and to the rotation angle as theoretically proved.
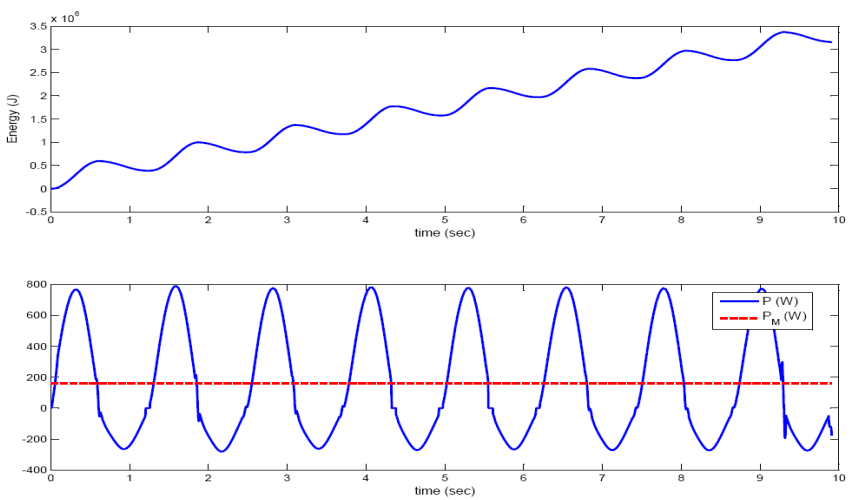

Fig. 11. Orbit 2's Power Generation, $P_{M}$ mean power
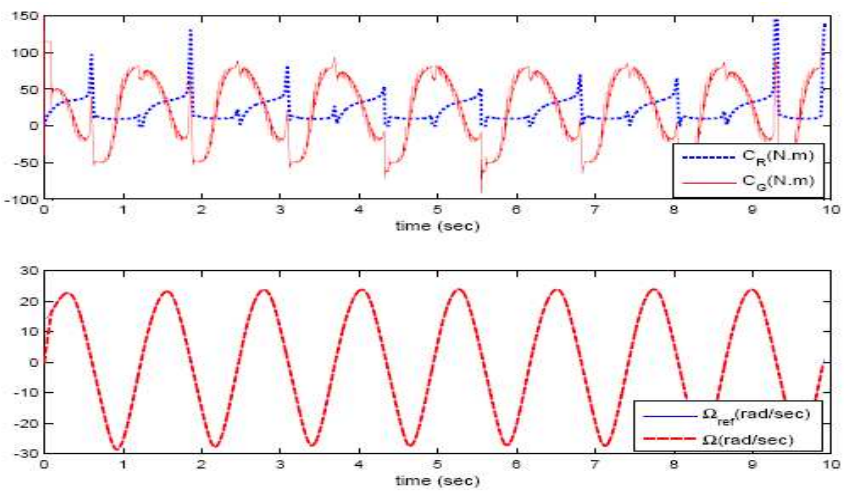

Fig. 12. Kite applied torque $\left(C_{R}\right)$, Generator Torque $\left(C_{G}\right)$ and Rotation velocity tracking for orbit 2 .

\section{B. Further Works}

This work is a part of a collaboration project between Gipsa-lab and G2ELab. A reduced kite's model is under construction. The theoretical results in this paper will be applied to a HIL (Hardware in the loop) physical simulator,
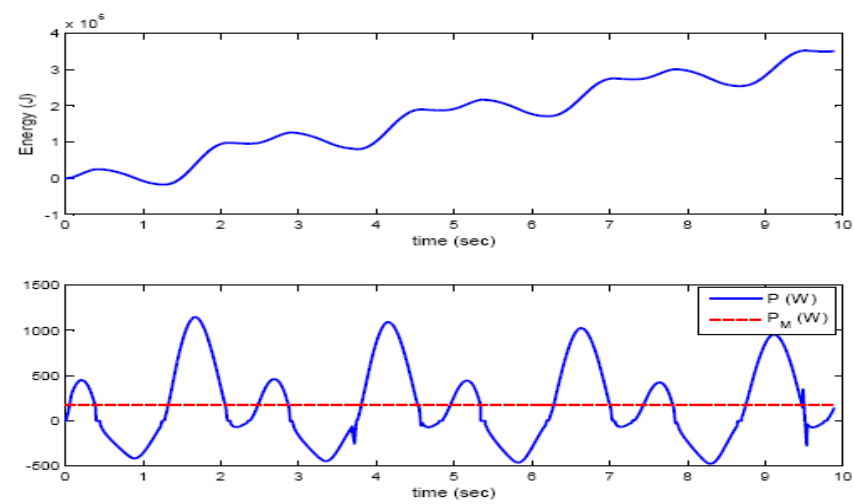

Fig. 13. Orbit 3's Power Generation, $P_{M}$ mean power.
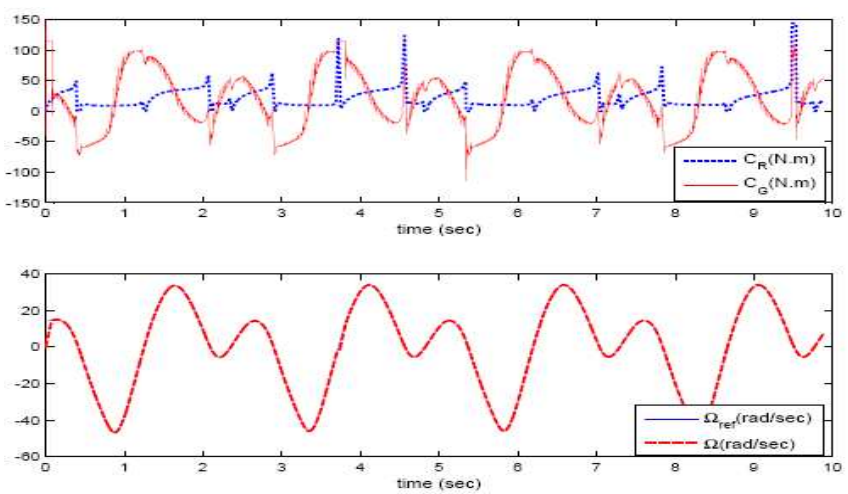

Fig. 14. Kite applied torque $\left(C_{R}\right)$, Generator Torque $\left(C_{G}\right)$ and Rotation velocity tracking for orbit 3 .

that is dedicated to real-time validation of control laws with insertion of physical elements that contribute to better replication of the real phenomena [10].

\section{REFERENCES}

[1] M. Ahmed, A. Hably, and S. Bacha. Grid-connected kite generator system: Electrical variables control with mppt. In IECON, 2011.

[2] I. Argatov, P. Rautakorpi, and R. Silvennoinen. Estimation of the mechanical energy output of the kite wind generator. Renewable Energy, 34:1525-1532, 2009.

[3] I. Argatov and R. Silvennoinen. Energy conversion efficiency of the pumping kite wind generator. Renewable Energy, 35(5):1052-1060, 2010.

[4] M. Canale, L. Fagiano, M. Ippolito, and M. Milanese. Control of tethered airfoils for a new class of wind energy generator. In Proceedings of the 45th IEEE Conference on Decision and Control, 2006.

[5] M. Canale, L. Fagiano, and M. Milanese. High altitude wind energy generation using controlled power kites. IEEE Transactions On Control Systems Technology, 18(2):279 - 293, 2010.

[6] M. Diehl. Real time optimization for Large Scale Nonlinear Processes. $\mathrm{PhD}$ thesis, University of Heidelburg, 2001.

[7] http://www.jobyenergy.com/.

[8] http://www.makanipower.com/

[9] M. Arnaiz martin. Modeling and control of kites for electric energy generation. Master's thesis, Grenoble INP, 2010.

[10] I. Munteanu, A.I. Bratcu, S. Bacha, D. Roye, and J. Guiraud. Hardware-in-the-loop-based simulator for a class of variable-speed wind energy conversion systems: Design and performance assessment. IEEE Transactions On Energy Conversion, 25:564-576, JUNE 2010.

[11] P. Williams, B. Lansdorp, and W. Ockels. Optimal cross-wind towing and power generation with tethered kites. In AIAA Guidance, Navigation and Control Conference and Exhibit, 2007. 